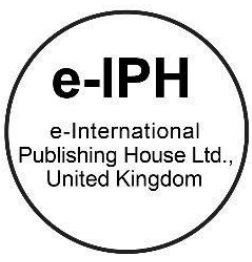

\title{
Effect of Galleries on Thermal Conditions of Urban Open Areas
}

\author{
Shahab Kariminia * \\ Department of Architecture, Faculty of Art, Architecture and Urban Planning, \\ Najafabad Branch, Islamic Azad University, Najafabad, Isfahan, Iran
}

\begin{abstract}
Computer simulations were performed by ENVI-met model along with physical measurements in two urban squares under hot summer conditions in Isfahan, central Iran. Each scenario concentrated on adding or extending galleries in each square. The results confirmed the role of galleries on thermal conditions; however, it was found that the effectiveness of this strategy depends on the square geometry. It presented higher efficiency for the small square with higher H/W ratio. This solution is advisable for smaller squares and when the peripheral parts are frequently used compared to the middle areas. Galleries are most efficient when allow enough natural ventilation

(C) 2016. The Authors. Published for AMER ABRA by e-International Publishing House, Ltd., UK. Peer-review under responsibility of AMER (Association of Malaysian Environment-Behaviour Researchers), ABRA (Association of Behavioural Researchers on Asians) and cE-Bs (Centre for Environment-Behaviour Studies), Faculty of Architecture, Planning \& Surveying, Universiti Teknologi MARA, Malaysia.
\end{abstract}

Keywords: Urban open area; urban geometry; simulation; galleries

\section{Introduction}

Urban climate has been affected by the rapid development of cities (Kariminia, Sh Ahmad, Ibrahim, \& Omar, 2010) along with the global climate change (Kariminia, Ahmad, \& Hashim, 2012; Kariminia, Ahmad, Hashim, \& Ismail, 2013). Research area of urban climate, which consists of thermal, energetic, wind flow and pollution issues (Ali-Toudert \& Mayer, 2007) Thermal conditions outdoor is one of the factors influencing the number of visitors and amount of their activities in urban streets, squares, parks, etc. the level of the discomfort experienced by the inhabitants once they are exposed to the urban microclimatic conditions depends on various parameters (Nasir, Ahmad, \& Ahmed, 2013). Amelioration techniques encourage visitors to stay outdoors under hot conditions. Within urban spaces, squares are less noticed rather than canyons and parks (Kariminia, Ahmad, Omar, \& Ibrahim, 2011; Kariminia \& Ahmad, 2013). Moreover, in few studies concentrated on squares, they are typically described as a simple rectangular or circle shape. Nevertheless, in real cases, urban square geometry can be more complex, as to be asymmetrical, or include design arrangements on the facades or at street level (Taleghani, Kleerekoper, Tenpierik, \& van den Dobbelsteen, 2015). The issue of solar access has been increasingly noticed (Bourbia \& Awbi, 2004). Inside an open urban space, lower height buildings in southern side allow the opposite north walls large period of receiving sun radiation in winter.

* Corresponding author. Tel.: +983142292295; fax: +983142291016.

E-mail address: sh.kariminia@par.iaun.ac.ir

(C) 2016. The Authors. Published for AMER ABRA by e-International Publishing House, Ltd., UK. Peer-review under responsibility of AMER (Association of Malaysian Environment-Behaviour Researchers), ABRA (Association of Behavioural Researchers on Asians) and cE-Bs (Centre for Environment-Behaviour Studies), Faculty of Architecture, Planning \& Surveying, Universiti Teknologi MARA,

DOI: https://doi.org/10.21834/e-bpj.v1i2.1216 
By contrast, either to shade the facade or to protect the pedestrian level, the facades are sometimes offset over the open area. It can be observed in traditional architectures of Middle East region such as moucharabiehs, portico or galleries (Ali-Toudert \& Mayer, 2007). These design concepts have inspired the contemporary architecture to use detail arrangements as climatic control strategies in open spaces (Capeluto, 2003).

Nevertheless, this use is tested by very limited number of published studies from the thermal point of view, mostly on urban canyon (Littlefair et al., 2000). Based on advance models, Ali-Toudert (2005) investigated the correlation between urban canyon design and outdoor thermal comfort under hot and dry climate of Algeria lying on $32.40^{\circ} \mathrm{N}$ and $3.80^{\circ}$ E. Various cases with different orientations (i.e. N-S, E-W, NE-SW and NW-SE), H/W ratios $(0.5,1,2,3$ and 4$)$ and architectural details (galleries and overhangs) were compared by using threedimensional ENVI-met 3.0 simulation model. It was argued that improvement of outdoor thermal comfort is possible by the modification strategies in such extreme climate (Kariminia, Sh Ahmad, \& Ibrahim, 2013). Limiting solar exposure through applying appropriate solar orientations, ratios and shading devices was addressed as the main strategy to mitigate thermal stress. Similarly, Berkovic, Yezioro, and Bitan (2012) numerically studied outdoor thermal comfort in an enclosed courtyard by using ENVI-met 3.1 model. The effects of shading and wind were been evaluated by monitoring thermal circumstances in different scenarios designed in regard to the openings, trees, galleries and horizontal shading devices. In summertime, thermal comfort showed reliance mainly on Rs and the contribution of wind in improving the conditions was limited in comparison with the shading. The researchers addressed the amount of shade by the orientation of the courtyard and reported the elongated E-W rectangular courtyard as the most radiated case. They argued that ventilations by openings increase the penetration of hot air and radiation which in turn increases temperature in the courtyard. Applying trees and galleries was recommended by this study as the sufficient strategies.

In Iran, the use of portico and galleries as shading device is known in both traditional and contemporary architecture, particularly in the hot regions of the country. However, only very limited number of researches have systematically investigated the amelioration role of such devices using simulation models (Kariminia, Motamedi, et al., 2015) and more focused on the geometry (Kariminia, Ahmad, \& Saberi, 2015). This study aims to quantitatively evaluate the microclimatic circumstances at two urban squares with regard to the thermal role of the colonnades.

\section{Methodology}

Thermal simulation models are normally designed to simulate current environmental status and predict microclimatic changes with respect to landscape modification characteristics. They actually can compare the situations that are not feasible to provide in actual at least in the current time or for a longer period of time. Additionally, they are able to evaluate the preciseness of the measured data. Indeed, their versatility in encountering various micro and outcome variables make them more applicable (Arnfield, 2003). The simulation models are developed based on different schemes and spatial resolutions e.g. macroscale or microscale. Meanwhile, microscale models are appropriate for urban design prognoses. At this scale, three-dimensional (3D) wind flow models are well-developed and most-called in comparison with very time-consuming hydrological models (AliToudert, 2005). Indeed, they are faster and more accurate based on the function of turbulence scheme (Arnfield, 2000). Furthermore, 3D flow- based models consider spatial differences within an urban space compared with models that plot the space as a whole (Ali-Toudert, 2005). CAD-based models reproduce a 3D scheme of the domain and take the interdependence between indoors and outdoors into account.

\subsection{ENVI-met model}

ENVI-met 3.1 is a 3D non-hydrostatic microclimate model with a wide range and detailed output variable prognosis. It was originally designed by Prof. Bruce of University of Mainz, Germany and was developed in collaboration with Flemish Institute for Technological Research (VITO) (Ali-Toudert, 2005). This is actually a surface-plant-air model with a high spatial resolution, consisted of three models, namely soil, radioactive fluxes transfer and vegetation which is able to represent various outputs produced from few and easy measured input variables. The model also includes a comprehensive database on surface and plant species. The high performance and accuracy of this model was found to be confirmed in previous studies (Ali-Toudert \& Mayer, 2007; Fahmy \& 
Sharples, 2009). According to the mentioned benefits, hence, ENVI-met 3.1 was applied in the present study to compare microclimates at actual situation and the modified situations over stipulated time frame.

\subsection{Simulation procedure}

To explore the influence of galleries on thermal situations of the squares, each one was simulated based on the actual situation (base model) along the proposed scenarios. Actually, there is no colonnade in Naghsh e Jahan Square while Jolfa Square has a $7 \mathrm{~m}$ high and $2 \mathrm{~m}$ wide portico at all sides. In the proposed scenarios, $12 \mathrm{~m}$ wide galleries were added to Naghsh e Jahan Square at the height of $15 \mathrm{~m}$ (same height as the square wall) and the galleries in Jolfa Square widened up to $5 \mathrm{~m}$. Although numerous data sets were estimated at the determined receptors, in order to obtain more accurate results, the data gained at the centre point of each square were applied (coincided with physical measurements at P3). However, for some scenarios, thermal situations in other areas of the squares were sought as well. ENVI-met automatically divides the first vertical grid into 5 parts. Hence, according to the defined size of grid cells, the most appropriate level, close to the human height i.e. $1.4 \mathrm{~m}$ was chosen. All simulations were conducted for a single day namely 29 July. According to the aim of simulation which is comparing different environmental situations, one day of comparison was efficient. The followings explain output of the simulation processes.

\section{Results and Discussions}

\subsection{Microclimates}

On the whole, thermal situations at the centre of Naghsh e Jahan Square did not vary substantially even by adding lateral $12 \mathrm{~m}$ wide galleries. Nevertheless, Jolfa Square showed different thermal conditions when assigned with widened galleries. Figure 1 represents Ta at the centre point of the squares concerning the proposed scenarios. Before 11:00, Jolfa Square is cooler compared to Naghsh e Jahan Square. However, after this time, when the sunlight is high and both squares are mostly irradiated, the temperature is lower at the larger square. Moreover, the $3 \mathrm{~m}$ widened galleries reduced the Ta by $1{ }^{\circ} \mathrm{C}$ at the smaller square. This cooling effect is more effective after 12:00.

The solar access patterns at the centre point of the squares did not vary by widening the lateral galleries (Figure 2). Only at 18:00 the centre area of Naghsh e Jahan Square is protected by the added galleries due to the low angle of sunlight. However, Figure 3 shows that the peripheral areas of the squares are more protected by the extended galleries. This effect is more efficient in the smaller square with lower SVF (Jolfa Square). In total, the gallery in the western side is more successful on solar obstruction in the afternoon for both squares. According to the orientation of Naghsh e Jahan Square $\left(-15^{\circ}\right)$, the northern galleries are effective as well. The centre areas of the squares remain irradiated the whole day. It is noted that the square with lower SVF experiences less irradiations before 9:00 and after 16:00 even at the centre point.

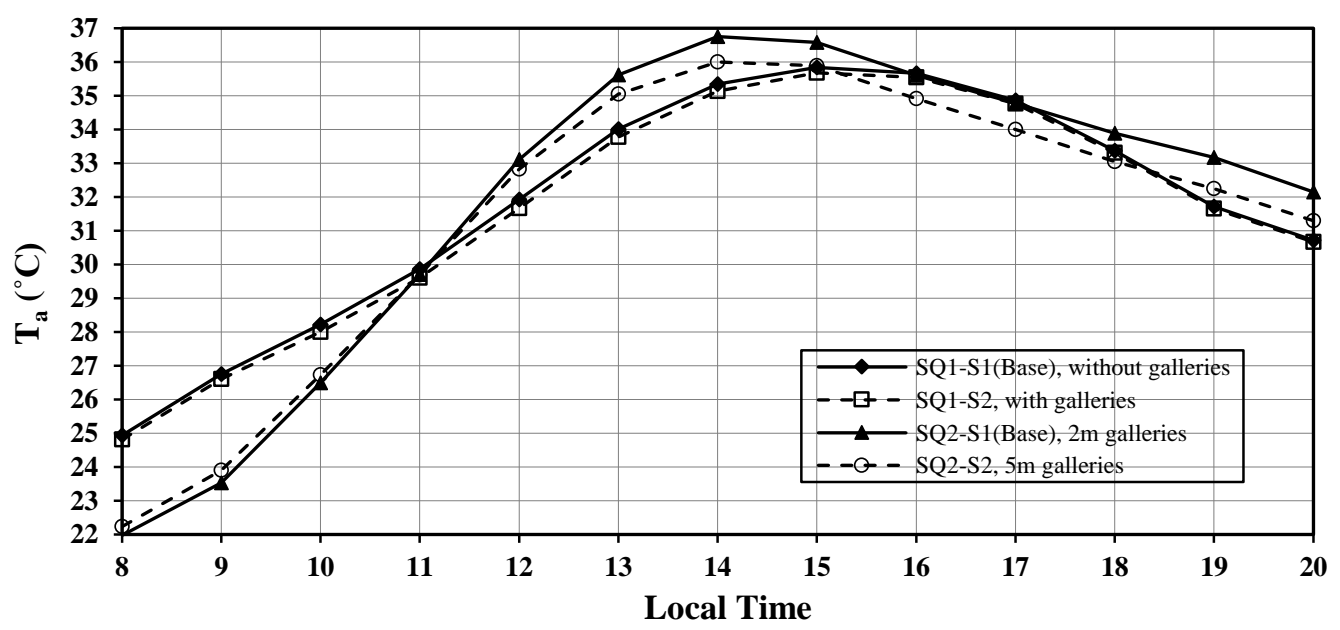

Fig.1 Daily Course of $\mathrm{T}_{\mathrm{a}}$ at the Centre Point of the Square Affected by Galleries 


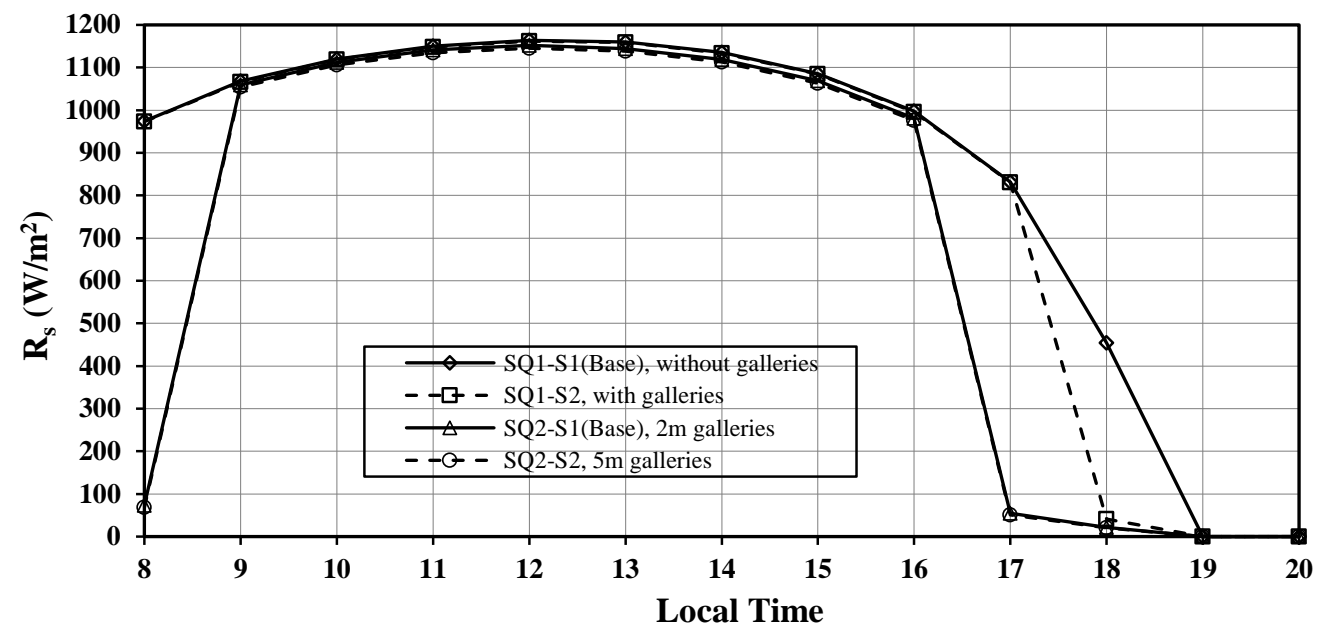

Fig. 2 Daily Course of $R_{s}$ at the Centre Point of the Square Affected by Galleries
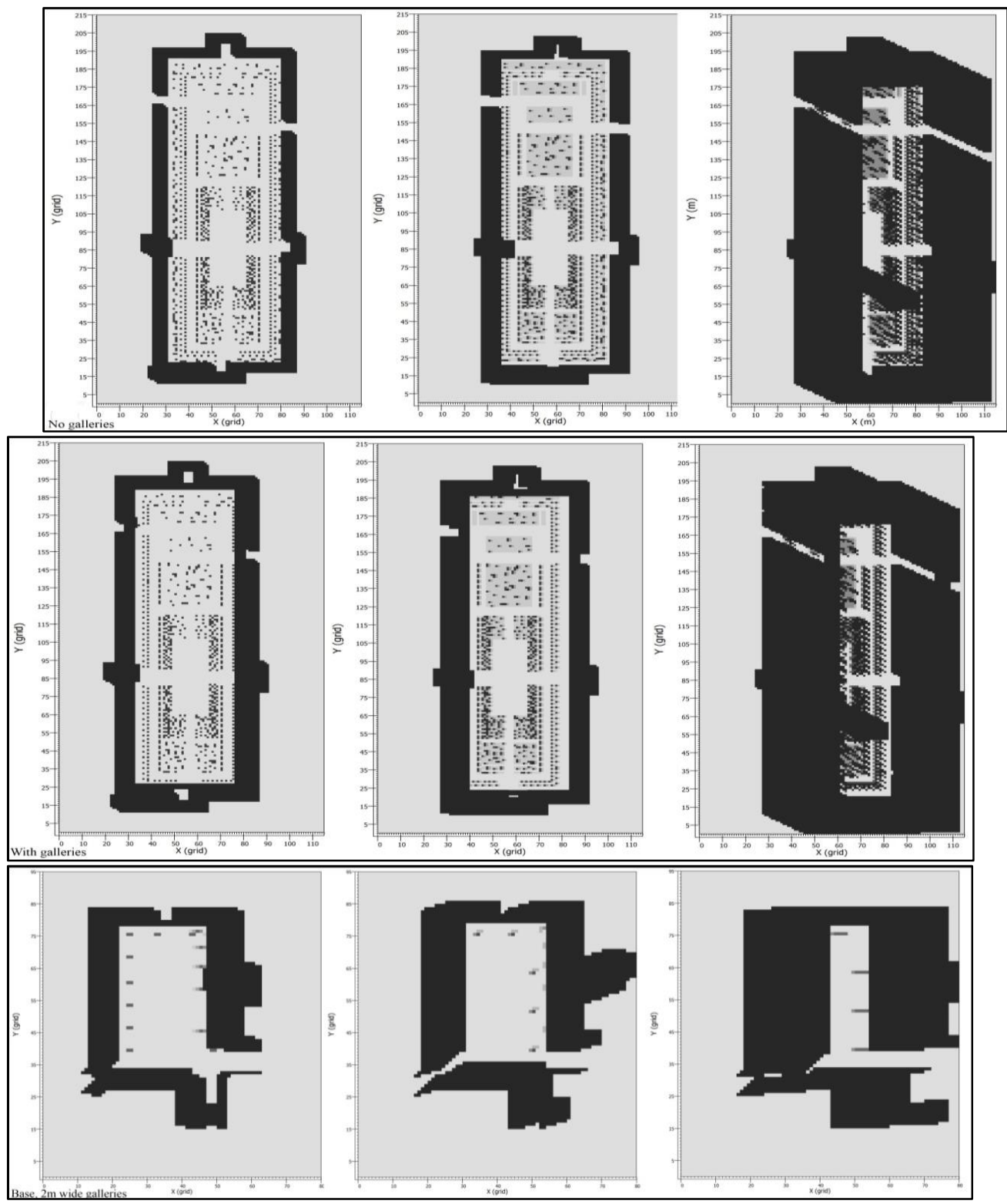


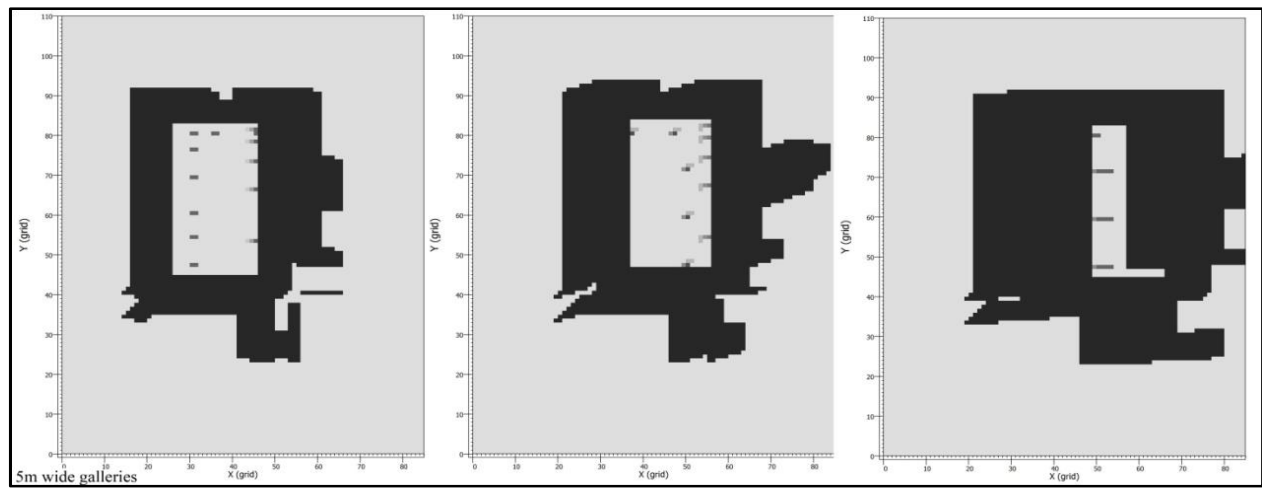

Fig. 3 Solar Access Differences of two squares by galleries at 10:00, 15:00 and 17:00

As was expected, widening galleries reduced the air velocities in the squares (Figure 4). This influence was stronger in Jolfa Square due to its smaller size where $W_{\mathrm{s}}$ equaled to only $0.3 \mathrm{~m} / \mathrm{s}$ in the evening and only $0.2 \mathrm{~m} / \mathrm{s}$ at 20:00. The lower ventilations can contribute to the higher thermal stress particularly when the square is highly uncomfortable in the afternoon. According to the low SVF, the air circulation within the small square thoroughly deviates from the original direction of the above-roof wind (Figure 5). By contrast, there is no major obstruction around the centre point of the large square and therefore, the $W_{\text {dir }}$ agrees with the east-directed overlying blows. Figure 6 shows the temporal daily $\mathrm{RH}$ for the four models. The air inside the smaller square is considerably drier than that in the large square where $\mathrm{RH}$ equals to roughly $4 \%$ lower at 12:00. However, considerable effect is not observed for individual squares made by widened galleries. The small differences in Jolfa Square can be related to the $\mathrm{T}_{\mathrm{a}}$ variances which oppositely impacts the value of $\mathrm{RH}$.

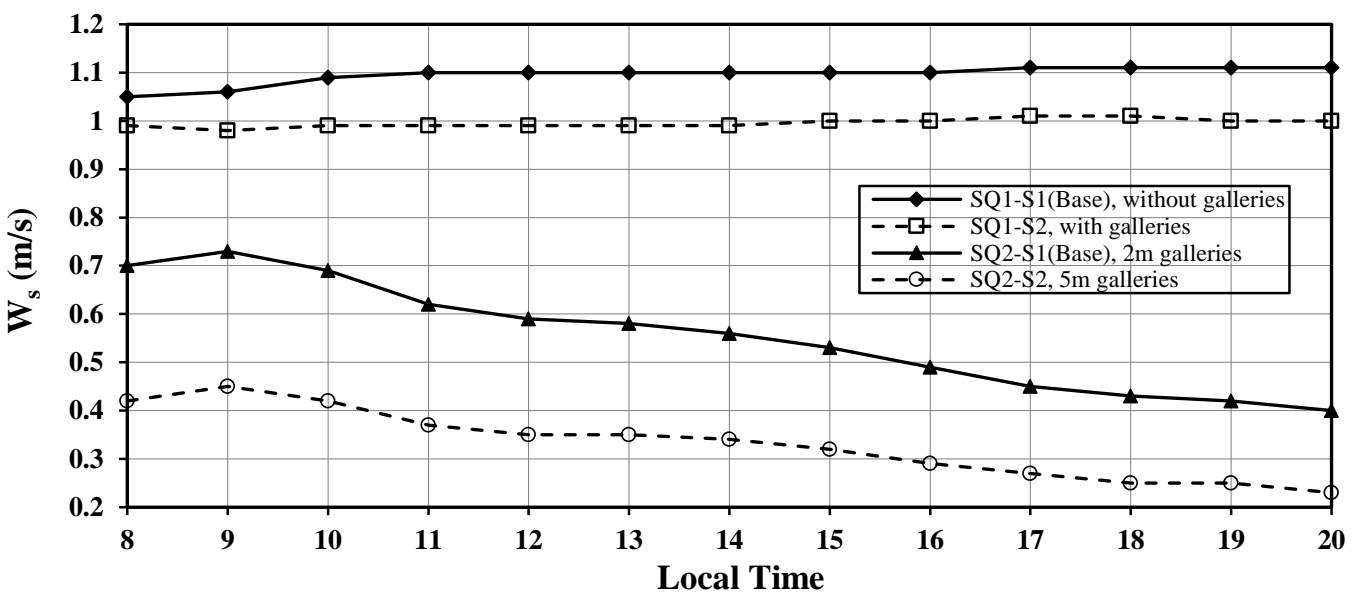

Fig. 4 Daily Course of $\mathrm{W}_{\mathrm{s}}$ at the Centre Point of the Square Affected by Galleries 


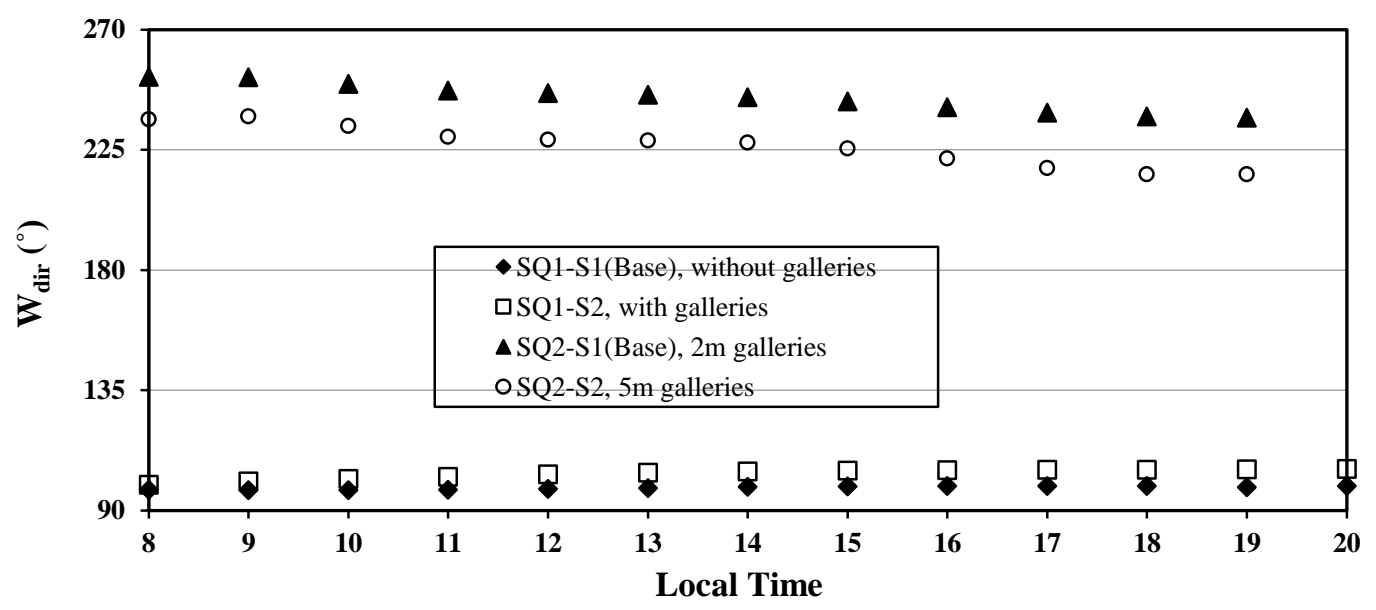

Fig. 5 Daily Course of Wdir at the Centre Point of the Square Affected by Galleries

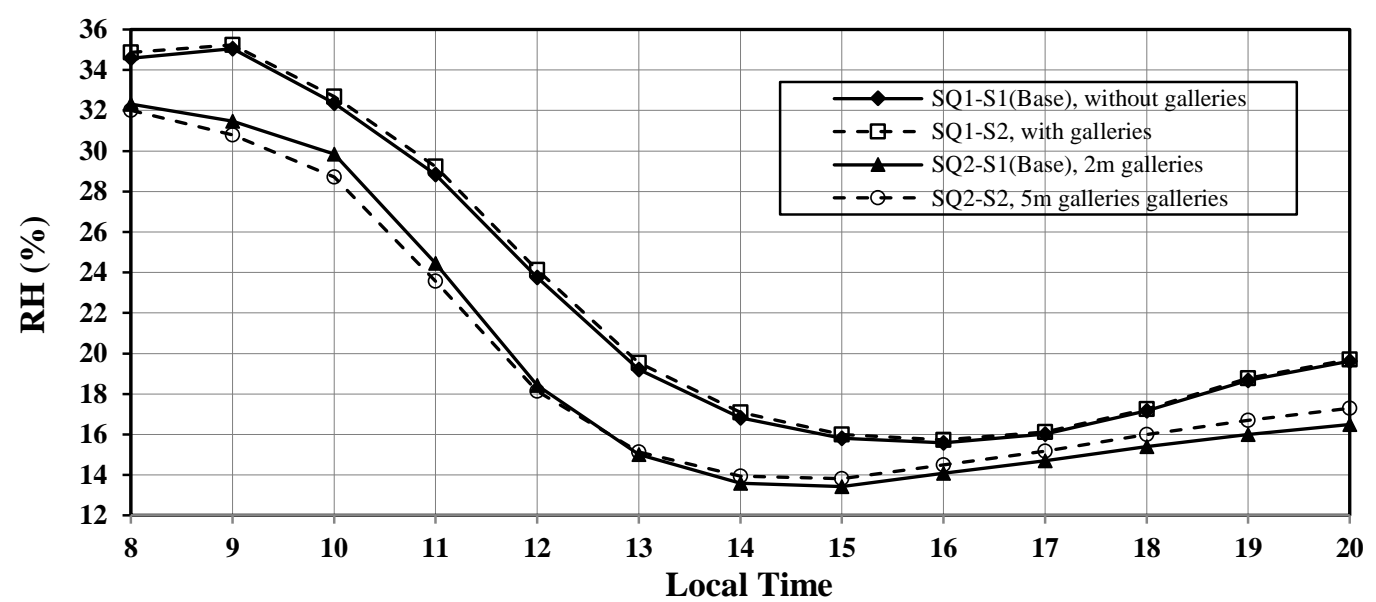

Fig. 6 Daily Course of RH at the Centre Point of the Square Affected by Galleries

\subsection{Thermal Comfort}

Figures 7 and 8 represent daily courses of $T_{m r t}$ and PET at the centre points of the squares. The radiant temperature does not vary widely between the actual and proposed profiles for each square. In total, thermal stress was higher in Jolfa Square. Furthermore, the actual profile of this square registered lower thermal stress compared with the proposed profile. This is attributed to the lower air velocities in the square caused by extended galleries. The maximum difference of PET between the actual and proposed scenarios of Jolfa Square equals to $3.3^{\circ} \mathrm{C}$ at $10: 00$. It was only $1.2{ }^{\circ} \mathrm{C}$ at the most stressful time of the day. Affected by the widened galleries, the proposed model of this square registered the high PET of $60^{\circ} \mathrm{C}$ at 15:00. However, for this square, before 10:00 and after 16:00, the two schemes show similar thermal conditions. On the other hand, a person standing at the centre of Naghsh e Jahan Square encounters similar thermal conditions for the models with and without galleries. As a result, for the urban spaces with low SVF, side galleries contribute to higher hot stresses at the middle areas (due to lower ventilations). This disagrees with the results of the study conducted on urban canyons by AliToudert and Mayer (2007) 


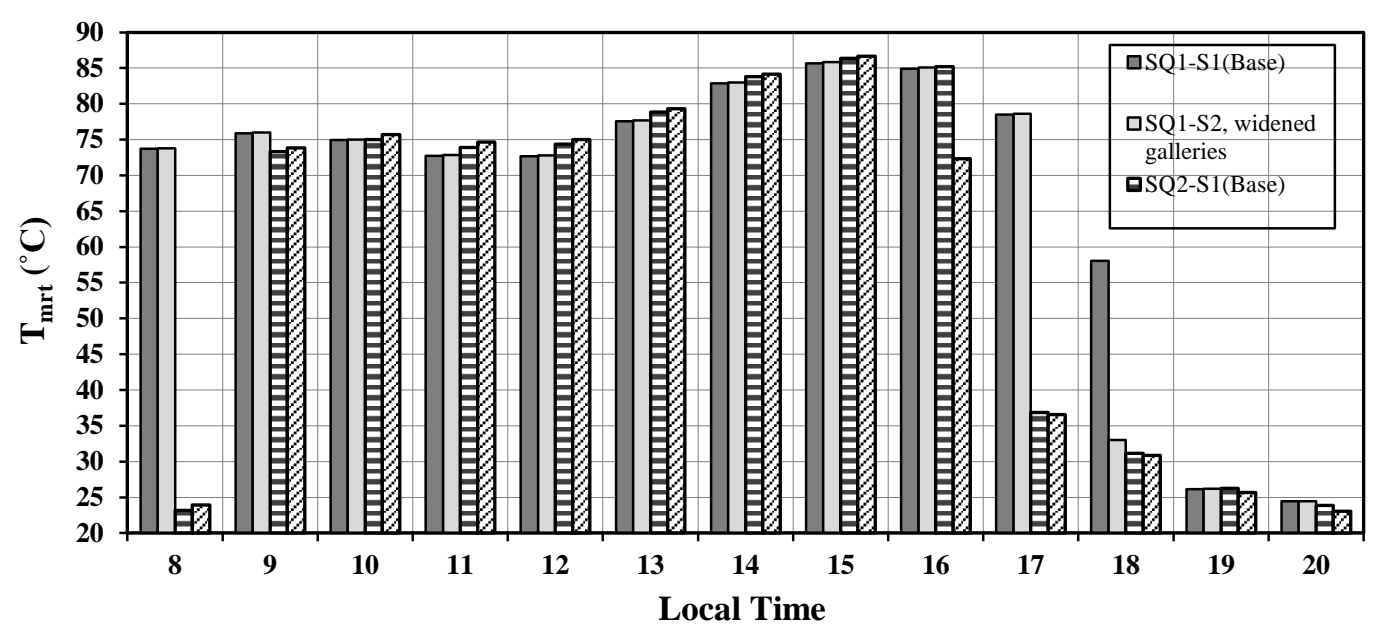

Fig. 7 Daily Course of $\mathrm{T}_{\mathrm{mrt}}$ at the Centre Point of the Square Affected by Galleries

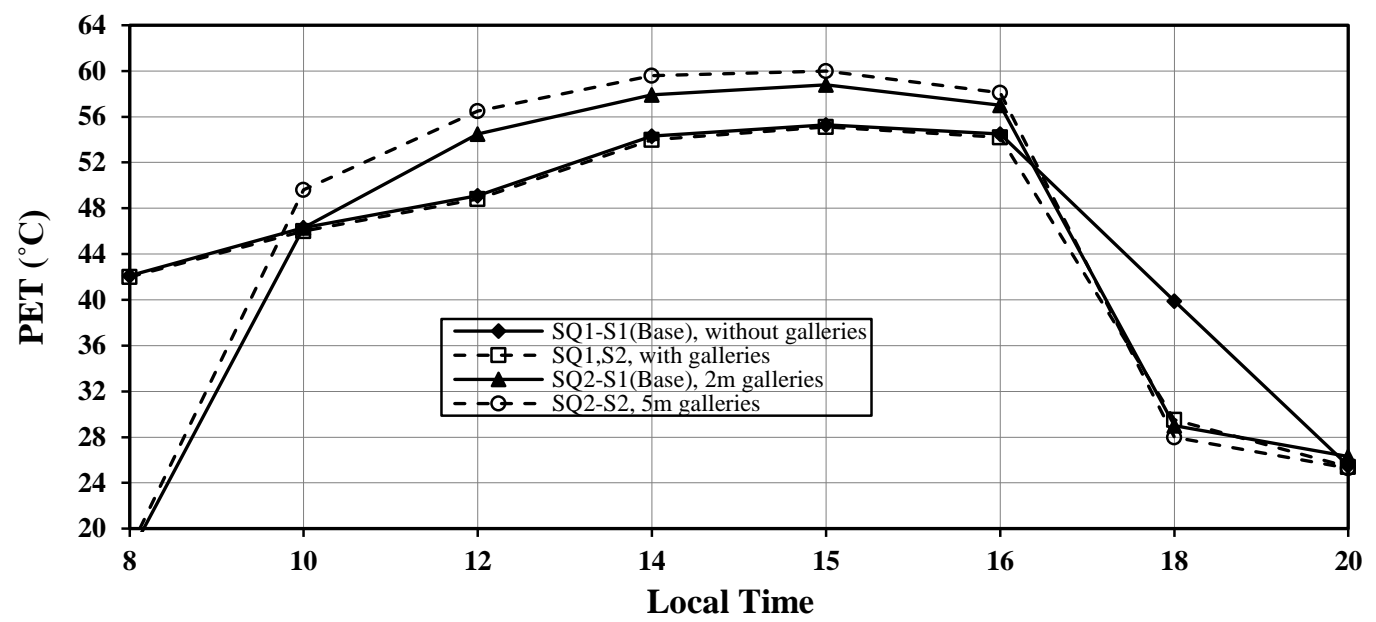

Fig. 8 Daily Course of PET at the Centre Point of the Square Affected by Galleries

In order to provide a comprehensive view on the thermal situations at the entire area of the squares, PET values were also estimated at the peripheral areas. Figure 9 reveals the determined points A1-5 within the Squares. The north western area next to the opening of western faced, the north eastern area in front of the eastern opening and the middle eastern area on the road were chosen as A1, A2 and A3, respectively. The south western and south eastern quarters next to the facades were symbolized respectively by $A 4$ and $A 5$, representing the situations next to the builtup area. Table 1 lists the thermal conditions at peripheral points of the two squares. Two points A4 and A5 in Naghsh e Jahan Square and the point A5 in Jolfa Square were under the galleries. In Naghsh e Jahan Square, PET under the galleries of the proposed model is lower than that of the same place in the actual model. At A4, in the south western area, the thermal condition is highly ameliorated whereas the PET difference is nearly $29^{\circ} \mathrm{C}$ at $10: 00$. At the most stressful daily hour, $\mathrm{A} 5$, in the south eastern quarter of the profile with the galleries experiences $2.3^{\circ} \mathrm{C}$ lower PET than that at the same location in the profile without galleries. No systematic cooling effect was observed for the non-covered locations in this square even near the galleries.

In Jolfa Square, A5 in the southern part is covered in the two actual and proposed models and hence, registers no higher difference than $1.2^{\circ} \mathrm{C}$ PET at 15:00 between two actual and proposed models. Yet, at the eastern part, even the non-covered locations of A2 and A4 near the galleries show substantial improvement by widening galleries. Surprisingly, PET at the north eastern corner is approximately $30^{\circ} \mathrm{C}$ lower for the proposed model compared to the actual model. It is 
worthy to note that this point is at one grid distance from the covered part by extended galleries. At the hottest time, A4 experiences $5.4^{\circ} \mathrm{C}$ lower PET in the square with widened galleries. At the north eastern area of the actual model with only $2 \mathrm{~m}$ galleries, the level of discomfort is considerably high at $15: 00$ and reaches nearly $62{ }^{\circ} \mathrm{C}$ PET. This is controlled down to $59^{\circ} \mathrm{C} \mathrm{PET}$ after widening the galleries. As a result, for small size spaces, widening the galleries is a useful strategy to mitigate the hot conditions and not only for covered areas. It works more efficiently for the eastern parts of the spaces. However, for larger squares and lower H/W ratios, it is not a decisive strategy even for covered areas.

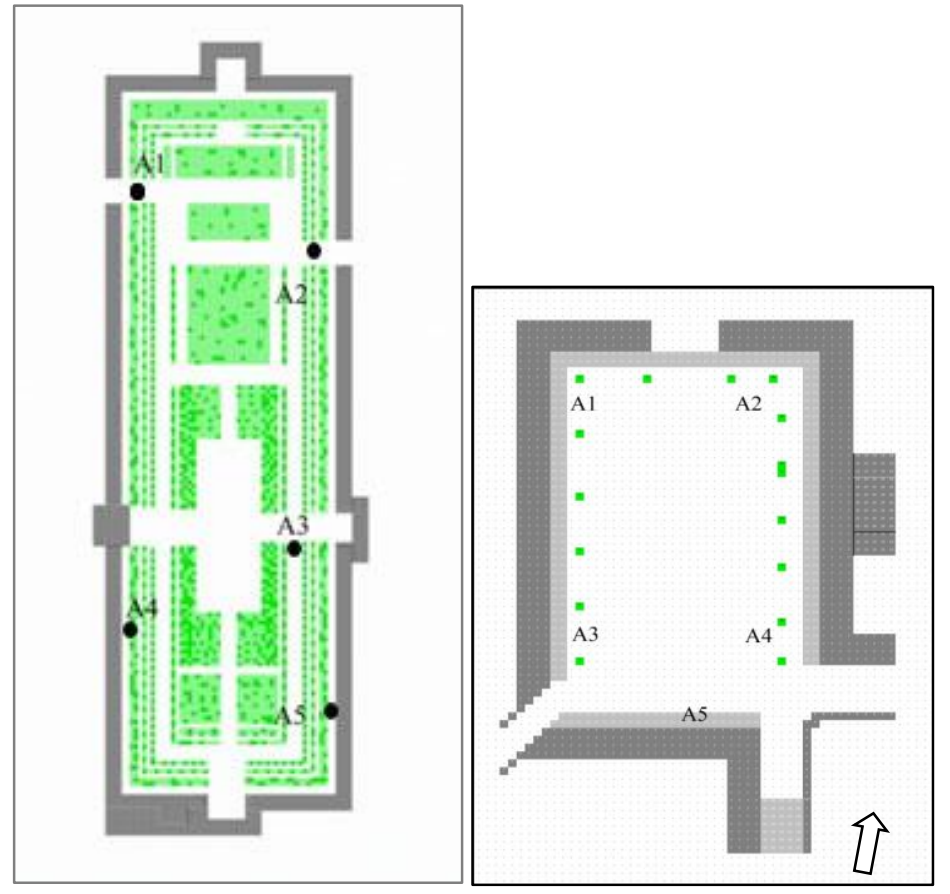

Fig. 9 Peripheral Locations Chosen to Investigate Thermal Situations at two Squares

Table 1 Thermal Conditions at Lateral Points in the Both Squares

\section{PET $\left({ }^{\circ} \mathbf{C}\right)$}

\begin{tabular}{ccccccccccccc}
\hline \multicolumn{1}{c}{ Naghsh e Jahan Square } \\
\hline \multicolumn{1}{c}{ Without galleries } & \multicolumn{3}{c}{ With galleries } & \multicolumn{3}{c}{ Jolfa Square } \\
\hline & $10: 00$ & $15: 00$ & $20: 00$ & $10: 00$ & $15: 00$ & $20: 00$ & $10: 00$ & $15: 00$ & $20: 00$ & $10: 00$ & $15: 00$ & $20: 00$ \\
\hline A1 & 48.1 & 56.6 & 25.3 & 48.6 & 56.8 & 25.3 & 51.8 & 32 & 27 & 53.4 & 30.4 & 26.5 \\
A2 & 48.6 & 56.9 & 25.2 & 47.9 & 57 & 25.8 & $\mathbf{5 1 . 7}$ & $\mathbf{6 1 . 7}$ & 27 & $\mathbf{2 2 . 3}$ & $\mathbf{5 8 . 9}$ & 26.4 \\
A3 & 50 & 57.8 & 25.3 & 50.2 & 58.6 & 25.2 & 48.6 & 34 & 27.5 & 49.3 & 32.1 & 27.1 \\
A4 & $\mathbf{5 2 . 9}$ & 32 & 24.8 & $\mathbf{2 4}$ & 30.8 & 24.9 & $\mathbf{3 8 . 1}$ & $\mathbf{5 1 . 3}$ & 28.2 & $\mathbf{2 2}$ & $\mathbf{4 5 . 9}$ & 27.7 \\
A5 & 24.4 & $\mathbf{5 9 . 3}$ & 25.2 & 23.3 & $\mathbf{5 7}$ & 24.9 & 21.9 & 34.4 & 27.9 & 21.3 & 33.2 & 27.3 \\
\hline
\end{tabular}

\section{Conclusions}

In previous studies, using galleries was shown to be beneficial for controlling thermal heat stress as the consequence of less direct irradiations received by the human body and lower longwave fluxes emitted from the surrounding surfaces (Swaid, Bar-El, \& Hoffman, 1993). 
Nevertheless, this study found that the effectiveness of this strategy depends on the square geometry. Widening the galleries increased the area and duration of the shading only at the peripheral areas of the squares. A large part of Naghsh e Jahan Square did not reveal any considerable change in the $\mathrm{T}_{\mathrm{a}}$ and PET caused by the added galleries, except for a small part. In fact, due to shallower profile, the shaded area provided by the galleries was quite small even under the galleries. In Jolfa Squre, the ratio of the widened galleries to the total area of the square was much higher (7 times more than Naghsh e Jahan Square), hence, the reduction of $W_{s}$ was higher. Albeit, widened galleries slightly reduced the $\mathrm{T}_{\mathrm{a}}$ in the middle areas, the higher wind obstructions led to a higher thermal stress in this square (up to $3.5^{\circ} \mathrm{C} \mathrm{PET}$ ). By contrast, efficient amelioration effect was observed at the peripheral areas even within the non-covered parts. As a result, this solution is advisable for smaller squares and when the peripheral parts are frequently used compared to the middle areas. Galleries are most efficient when allow enough natural ventilation. The findings can be useful for urban planners to consider the size and geometry of urban open spaces while galleries in such places.

\section{Acknowledgement}

Funding for the equipment used for the field study was made possible in part by the Research Management Institute's Excellence Fund, UiTM, Malaysia. Besides, supports of Islamic Azad University, Najafabad Branch, Iran made the participation in the conference possible.

\section{References}

Ali-Toudert, F. (2005). Dependence of outdoor thermal comfort on street design in hot and dry climate. Universitätsbibliothek Freiburg.

Ali-Toudert, F., \& Mayer, H. (2007). Effects of asymmetry, galleries, overhanging facades and vegetation on thermal comfort in urban street canyons. Solar Energy, 81(6), 742-754.

Arnfield, A.J. (2000). A simple model of urban canyon energy budget and its validation. Physical Geography, 21(4), $305-326$.

Arnfield, A.J. (2003). Two decades of urban climate research: a review of turbulence, exchanges of energy and water, and the urban heat island. International Journal of Climatology, 23(1), 1-26.

Berkovic, Sigalit, Yezioro, Abraham, \& Bitan, Arieh. (2012). Study of thermal comfort in courtyards in a hot arid climate. Solar Energy, 86(5), 1173-1186.

Bourbia, F., \& Awbi, H. B. (2004). Building cluster and shading in urban canyon for hot dry climate:: Part 1: Air and surface temperature measurements. Renewable energy, 29(2), 249-262.

Capeluto, I Guedi. (2003). Energy performance of the self-shading building envelope. Energy and buildings, 35(3), 327-336.

Fahmy, M., \& Sharples, S. (2009). On the development of an urban passive thermal comfort system in Cairo, Egypt. Building and Environment, 44(9), 1907-1916.

Kariminia, S., Ahmad, S. S., Omar, M., \& Ibrahim, N. (2011). Urban outdoor thermal comfort prediction for public square in moderate and dry climate. Paper presented at the 2011 IEEE Symposium on Business, Engineering and Industrial Applications (ISBEIA), .

Kariminia, S., Sh Ahmad, S., \& Ibrahim, N. (2013). Landscape Attributes, Microclimate and Thermal Comfort of an Urban Square in Moderate and Dry Climate. Advanced Materials Research, 610, 3780-3784.

Kariminia, S., Sh Ahmad, S., Ibrahim, N., \& Omar, M. (2010). Outdoor thermal comfort of two public squares in temperate and dry region of Esfahan, Iran. Paper presented at the 2010 International Conference on Science and Social Research (CSSR), .

Kariminia, Shahab, \& Ahmad, Sabarinah Sh. (2013). Dependence of Visitors' Thermal Sensations on Built Environments at an Urban Square. Procedia - Social and Behavioral Sciences, 85(0), 523-534.

Kariminia, Shahab, Ahmad, Sabarinah Sh, \& Hashim, Rugayah. (2012). Assessment of Antarctic Tourism Waste Disposal and Management Strategies towards a Sustainable Ecosystem. Procedia - Social and Behavioral Sciences, 68(0), 723-734.

Kariminia, Shahab, Ahmad, Sabarinah Sh, Hashim, Rugayah, \& Ismail, Zulhabri. (2013). Environmental Consequences of Antarctic Tourism from a Global Perspective. Procedia - Social and Behavioral Sciences, 105(0), 781-791.

Kariminia, Shahab, Ahmad, Sabarinah Sh, \& Saberi, Ahmadreza. (2015). Microclimatic Conditions of an Urban Square: Role of Built Environment and Geometry. Procedia - Social and Behavioral Sciences, 170(0), 718-727.

Kariminia, Shahab, Motamedi, Shervin, Shamshirband, Shahaboddin, Piri, Jamshid, Mohammadi, Kasra, Hashim, Roslan, ... Bonakdari, Hossein. (2015). Modelling thermal comfort of visitors at urban squares in hot and arid climate using NN-ARX soft computing method. Theoretical and Applied Climatology, 1-14. doi: 10.1007/s00704-015-1462-6

Littlefair, P., Santamouris, M., Alvarez, S., Dupagne, A., Hall, D., Teller, J., . . Papanikolaou, N. (2000). Environmental site layout planning: 
solar access, microclimate and passive cooling in urban areas. London: CRC.

Nasir, Rabiatul Adawiyah, Ahmad, Sabarinah Sh, \& Ahmed, Azni Zain. (2013). Physical Activity and Human Comfort Correlation in an Urban Park in Hot and Humid Conditions. Procedia - Social and Behavioral Sciences, 105(0), 598-609.

Swaid, H., Bar-El, M., \& Hoffman, ME. (1993). A bioclimatic design methodology for urban outdoor spaces. Theoretical and Applied Climatology, 48(1), 49-61.

Taleghani, Mohammad, Kleerekoper, Laura, Tenpierik, Martin, \& van den Dobbelsteen, Andy. (2015). Outdoor thermal comfort with in five different urban forms in the Netherlands. Building and Environment, 83(0), 65-78. doi: http://dx.doi.org/10.1016/j.buildenv.2014.03.014 